Lisbon - Malacca Port Cities Twin Conferences 2019 / 2020

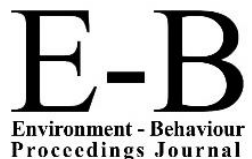

AicQoL2020Malacca

ASLI (Annual Serial Landmark International) Conferences on QoL2020

https://www.amerabra.org; https://fspu.uitm.edu.my/cebs; https://www.emasemasresources.com/

8th AMER International Conference on Quality of Life

Mahkota Hotel Melaka, Malacca, Malaysia, 18-19 Mar 2020

(Due to the Covid-19 lockdown, paper virtually presented on 25 Mar 2020)

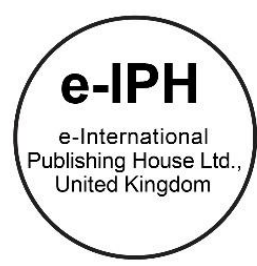

\title{
Drivers' Attitudes on Campus Roads: A review
}

\author{
Rugayah Hashim 1, Mohamad Ghazali Masuri ${ }^{2}$, Khairil Anuar Md Isa 2, Ayu Rohaidah Ghazali ${ }^{3}$ \\ ${ }^{1}$ Research \& Innovation Division, \\ 2 Faculty of Health Sciences, \\ 3 Faculty of Business \& Management, \\ Universiti Teknologi MARA, Selangor Branch, Malaysia
}

guy73106@yahoo.com, mghazali@uitm.edu.my, khairil996@uitm.edu.my, ayurohaidah@gmail.com

Tel. 0133852288

\begin{abstract}
Despite numerous campaigns on road safety for the university population, driving attitudes off campus is often reflected on campus. Thus, the paper reviews the literature on why traffic congestion and accidents occur on campus with a focus on drivers' attitudes. The scope of the investigation will be the students, staff, and other university stakeholders who regularly drive on campus. The approach for this paper is more of a literature review with narratives and descriptions of the campus topology. The analyses and interpretations of the literature were through systematic identification of themes and variables which will be discussed in the paper.
\end{abstract}

Keywords: Campus traffic; Driver attitude; Transport system planning; Driver behavior

eISSN: 2398-4287 @ 2020. The Authors. Published for AMER ABRA cE-Bs by e-International Publishing House, Ltd., UK. This is an open access article under the CC BYNC-ND license (http://creativecommons.org/licenses/by-nc-nd/4.0/). Peer-review under responsibility of AMER (Association of Malaysian Environment-Behaviour Researchers), ABRA (Association of Behavioural Researchers on Asians) and cE-Bs (Centre for Environment-Behaviour Studies), Faculty of Architecture, Planning \& Surveying, Universiti Teknologi MARA, Malaysia.

DOI: https://doi.org/10.21834/e-bpj.v5i13.1950

\subsection{Introduction}

Road safety on Malaysian roads and highways has been a perennial concern by the government and the ministry concerned. Traffic congestion, too, has become an everyday concern. Safe driving should be practiced everywhere. More so within the university campus. As reported by Alrukaibi, Ali, and Aljassar (2006), university students are aware of traffic rules, but a significant number appear to be oblivious to the speed limits imposed in campus confines. Also, distracted driving behaviors among college students are noticeably the primary cause of accidents with cellphone usage as the main fault factor (Hill et al., 2015). Anyhow, keeping to the traffic rules and regulations on roads, highways, streets, and lanes should be the ideal behavior and attitudes for all drivers. Similar attitudes are expected for the university populace when driving on campus roads. For the university citizens, commuting on campus for students and staff is a daily occurrence. The traffic flow depends on the ongoing semester at Universiti Teknologi MARA, Cawangan Selangor (UCS), Puncak Alam Campus. During these times, heavy traffic is observed on campus, with minor mishaps occurring every week. However, with the increase in student intake, the number of accidents reported on campus contradicts the drivers' attitudes. It is important to note that driving on campus includes those using motorbikes. The drivers are the students, staff and other stakeholders at the university. Notably, each university campus has its own unique landscaping, architectural designs, and road infrastructure and UCS's Puncak Alam Campus is well-known for its hilly terrain. Nonetheless, the drivers' attitudes when on campus roads should correlate to the mindset of those in an institution of higher education, hence the goal of the review paper is to establish a theoretical framework with regards to drivers' attitudes.

eISSN: 2398-4287 ( 2020. The Authors. Published for AMER ABRA cE-Bs by e-International Publishing House, Ltd., UK. This is an open access article under the CC BYNC-ND license (http://creativecommons.org/licenses/by-nc-nd/4.0/). Peer-review under responsibility of AMER (Association of Malaysian Environment-Behaviour Researchers), ABRA (Association of Behavioural Researchers on Asians) and cE-Bs (Centre for Environment-Behaviour Studies), Faculty of Architecture, Planning \& Surveying, Universiti Teknologi MARA, Malaysia.

DOI: https://doi.org/10.21834/e-bpj.v5i13.1950 


\subsection{Literature Review}

In reviewing pertinent literature, the methodology employed will be by setting parameters to the relevant word and terms in the online database searches. The sources were from book chapters, journal articles, and technical reports available on the online databases subscribed by the university. Additionally, theoretical reviews were conducted to examine and correlate relevant behavioral theories. In doing so, this exercise will help establish appropriate methods in explaining new or emerging research problems. Moreover, the findings from the investigation will allow the university administrators to consider alternative remedies and non-traditional transport patterns to alleviate traffic congestion on campus roads. This study is significant as the framework as a solution for campus traffic system can be applied for other university campus communities in Malaysia. The implications of the study will be the provision of cost-benefit analysis for future campus transport systems planning and implementation for the country.

\subsection{Driving and cellphone usage among young adults}

Mobile phone ownership is generally an essential item among adolescence nowadays (Davie, Panting, \& Charlton, 2004). It also had significantly transformed the ways of their daily living activities include in doing business (Palen, Salzman, \& Youngs, 2001), learning (Motiwalla, 2007), and others. It has now become a trend where across the country, many young adults are now adopting mobile phones for enhancing their ways of life. This trend has changed drastically where a decade ago, the mobile phone was seen as an impossible gadget to be owned (Karim, Darus, \& Hussin, 2006). With current economic prosperity that was enjoyed among many Malaysian contributed to the financial ability of the people to increase their quality of life includes the ability to own mobile phones. Some parents nowadays were becoming more financially independent and able to provide their children with more expensive communication devices that improve their 'means of communication and socialization.' For example, many parents provide a car or motorcycle to their children for mobilization inside and outside the university. Their communication and socialization activities always happen in every second of their living. This could be proven by the usage of mobile phones while driving becomes a common sight these days (McCartt, Kidd, \& Teoh, 2014). These two phenomena always combine and can contribute to a significant risk of an accident. As we know, driving is a complex process that involves eyes-hand-foot coordination (Fuller, 2000). Futile to coordinate shall contribute to road traffic accidents (RTA). Young people represent the highest number of accident cases (Chliaoutakis et al., 2002). It has been proven that the young drivers had the highest tendencies to use a mobile phone while driving compared with other groups of people (McCartt et al., 2014), and this behavior could lead to RTA. The evidence on the correlation between the young adult's internet addiction and usage of cell phones while driving is supported by Masuri, Samad, Dahlan, and Isa (2019).

Based on our previous study, we found that $66.6 \%$ of the participants used a mobile phone while driving. This finding was similar to those reported in Spain at 60\% (Gras et al., 2007) and New Zealand (57.3\%) (Sullman \& Baas, 2004). However, this finding considerably lower than the studies done in Finland (80\%) (Pöysti, Rajalin, \& Summala, 2005) and in Australia (77\%) (White, Hyde, Walsh, \& Watson, 2010). This could explain why young adults ignore traffic law. Other than that, the student's life is demanding, which requires them to multitask since they have a tight schedule, hence mobile phone usage while driving. This present study also found that the majority of the participant was less likely to use the hand-free device, with only $31.4 \%$ reported using it. However, this finding was considerably higher than the proportion reported in Spanish (14.3\%) (Gras et al., 2007) and New Zealand studies (17.2\%) (Sullman \& Baas, 2004). Though, as this was a cross-sectional study, it was not possible to say that the usage of hand free device encourages them to use a mobile phone while driving. Future research should further investigate in an attempt to answer this question. The reported mobile phone usage between male and female respondents while driving was no different in this study. The only significant difference observed in this study was that males use a mobile phone more frequently to make a call on urban roads. Similar results were obtained by Sullman and Baas (2004) and Gras et al. (2007), who both found that male drivers often use a mobile phone while driving. The possible explanation for this could be due that male is more certain compared to female while driving, and they more confident to take a risk. The majority of the respondents reported that they would not be speeding in order to reduce the risks associated with using a handheld phone while driving in both highway (77.6\%) and urban road (61.1\%). This reported behavior is higher compared to the study done in Spain (Gras et al., 2007). In the Spanish study, they found that only $26.6 \%$ (urban road) and $22.6 \%$ (highway) of the respondents reported that they reduce speed to reduce the risk. This could be due to that they feel safer and less risky if they can reduce speed when using a mobile phone while driving. Mobile phone use while driving is common among young adults yet preventable driving risk. Results from this review paper will showcase the factors on students' driving attitudes.

\subsection{Driving behavior and attitudes}

Driving behavior can be learned and unlearned as it is environmentally and culturally mediated (Chen, Wang, \& Duan, 2014). Many studies indicated that driving behavior is a primary safety concern (ibid). In China, for example, the 2008 traffic police report indicated that bad driving habits, poor understanding of other road users and, inferior respect for traffic regulations were the factors that contributed to traffic accidents (ibid). In relating driving behavior factors to this paper, education could also be the mediating factor for safe and courteous driving. On-campus roads, university students have tertiary education, but their driving behavior does not show proper compliance with road safety regulations in the university parameters.

The driving behavior of older adults is different from those of younger drivers, as shown from $83.5 \%$ of never getting any traffic offense tickets (Yeoh, Rashid, \& Chan, 2009). The driving practices of older drivers should be emulated by the younger set with $45 \%$ of good driving attitudes and $52 \%$ of safe driving practices. Aside from Yeoh et al. (2009), other findings from Mizenko, Tefft, Arnold, and Grabowski (2015) also showed that older drivers have a pro-traffic culture by their strong support for the laws and regulations. On another note, the younger generation has been shown to have personality and attitudes of risky driving behavior (Kong, Zhang, \& Chen, 2013). 


\subsection{Methodology}

This is a review paper; therefore, the analyses of the relevant literature through scoping comprised the main approach. Similar activities incorporating elements of qualitative design through traffic observations were evident, but the expected findings from the scoping reviews were mainly from systematic, thematic evaluations. The similar processes were taken from the works of Safarpour, Khorasani-Zavareh, and Mohammadi (2020). Although meta-analysis, as advocated by Schmidt and Hunter (2015), the simple analysis undertaken was from tabulations of relevant sources. Also, as posited by Callcut and Branson (2009), the systematic reviews utilized a defined method to summarize relevant studies and known data addressing a specific area. A total of 50 journal articles were read and downloaded from the Google Scholar, Scopus, Web of Science (WOS) databases. Elements of the scoping, narrative review were also incorporated into the methodology as this is the common practice in all disciplines (ibid). However, Callcut and Branson (2009 also cautioned that narrative reviews are notoriously biased because experts tended to rely on their expertise and experience and failed to perform a complete review of available literature. Nonetheless, precautions have been taken to review papers on neutral grounds methodologically; that is, there is no bias nor prejudice for the selected papers based on the search hits. As a condition of reliability and validity, the systematic review would counter the weaknesses of a narrative review (ibid) by refining the topic and making the search words more focused and accurate. In this case, the words used for search-relevant literature were "driving", "attitudes", "campus", "university", "students" and "staff". For example, for "driving attitudes" and "university," there were 415 document results on Scopus and 667 results on WOS with a period from 1970-2020. The scoping review methodology used for this paper fits the outcome anticipated in deriving elements of students' attitudes and driving behavior on campus roads.

\subsection{Findings}

The findings from the 50 articles reviewed showed the driving attitudes and behavior of young adults (see Figure 1). Everyday occurrences in the papers provoked the theoretical framework listing the factors such as bad driving habits, poor understanding of other road users, inferior respect for traffic regulations (whether on campus roads or otherwise), aggressive driving and, other driving behavior. The sub-factors on driving behavior include education, age, family background, safe driving, illegal driving, that is, driving without a license and, distracted driving, for example, cellphone usage while driving. The implications of the framework will be discussed in the next section.

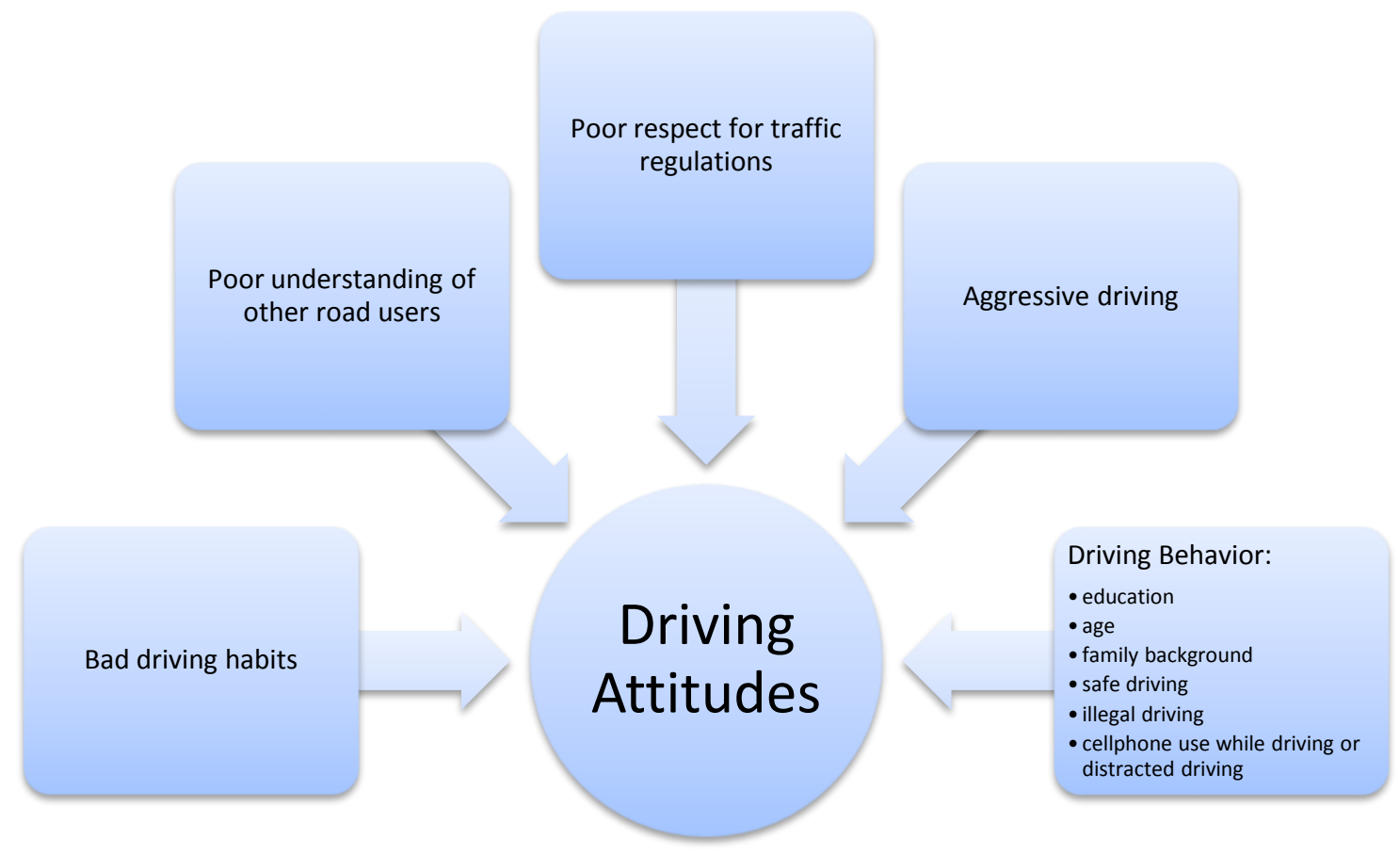

Fig. 1 Factors on Driving Attitudes

\subsection{Discussion}

From the five emerging factors on driving attitudes, several implications for further research and testing are suggested. For campus driving, the implications are varied but lean more towards driving behavior. In the driving behavior category, students and academic staff have higher learning backgrounds and qualifications. Even with that, the reported cases of campus accidents at UiTM Cawangan Selangor (UCS), Puncak Alam Campus (PAC) showed that tertiary education does not correlate to driving attitudes. For the university administrative staff of lower grades, there were no reported accidents on campus, but off-campus, several cases were noted. The data for the reported cases were tabled and presented by the head of the campus police department. The statistics could not be provided here because of confidentiality matters. One crucial variable for accidents was age. Again, based on the reports by the UCS campus 
police, most of the accidents (fatal and non-fatal) were among students. The age bracket for students at UCS PAC is between 18-25 for undergraduates. Therefore, this makes the driver's age as the main factor in driving attitudes on campus. Similar results were reported by Lucidi et al. (2019), where attitudes significantly predicted violations, errors, and lapses in young drivers aged between 18-24 years. Besides, accidents on UCS campus were found to be the young, student drivers' absorption with cellphone usage, which mirrors the findings by Zhu, Rudisill, Rauscher, Davidov, and Feng (2018). Hence, to corroborate the factors for driving attitudes on a university campus, it is recommended that that the conceptual framework identified (as in Fig. 1) be conducted as comprehensive research for empirical data. Zhu et al. (2018) have established that distracted driving while using the cellphone is the main factor of morbidity and mortality worldwide. To reiterate, the implications of these findings are crucial in reducing traffic accidents, whether on campus or outside. Law enforcement officers should also ensure that traffic offenders are given their dues. The factors on driving attitudes of young adults, which in this case are the university students. To reiterate Safarpour et al. (2020), the systematic approach to road safety will result in safer and courteous driving. Though human factors are to be blamed for road mishaps (Masuri, Asib, Dahlan, \& Isa, 2019), curtailing the attitudes through proper road education is recommended. Also, further studies on this issue are suggested by undertaking a quantitative method.

\subsection{Conclusion \& Recommendations}

From the literature surveyed, it can be concluded that the driving attitudes and behavior of the campus population, especially the students, require further investigation and support in the form of empirical evidence. Although human factors are the main cause of road accidents, the campus road layout and infrastructure could also be the reasons for the mishaps. Relevant government agencies under the Federal Ministry of Transport, for example, the Road Transport Department Malaysia, the Road Safety Department, the Malaysian Institute of Road Safety Research, and the Royal Malaysia Police, should be involved in inculcating good traffic attitudes. As a recommendation for further research, other theories should be studied to guide the investigation and should be ferreted for compatibility and practicality. For instance, there should be attempts to explore beyond cognitive behavior and undertake the Akers' social learning theory to determine the young road users' attitude and behavior. The significance and importance of these future findings will impact the traffic attitudes of young adults, particularly university students, when driving on and off-campus.

\section{Acknowledgment}

We are grateful for the research grants awarded to us by the Ministry of Education under the Fundamental Grant Scheme (FRGS) referenced 053/2017 and 126/2019. The former allowed for the publication of this article.

\section{References}

Alrukaibi, F., Ali, M. A., \& Aljassar, A. H. (2006). Traffic Safety Attitudes and Driving Behavior of University Students: Case Study in Kuwait. Transportation Research Record Journal of the Transportation Research Board 1969, 1, 6. doi:10.1177/0361198106196900109

Callcut, R. A., \& Branson, R. D. (2009). How to Read a Review paper. Respiratory Care, 54(10), 1379-2385.

Chen, F., Wang, M., \& Duan, L. (2014). Chapter 10 - Letting Drivers Know What is Going on in Traffic. In Y. Chen \& L. Li (Eds.), Advances in Intelligent Vehicles (pp. 291318). Boston: Academic Press.

Chliaoutakis, J. E., Demakakos, P., Tzamalouka, G., Bakou, V., Koumaki, M., \& Darviri, C. (2002). Aggressive behavior while driving as predictor of self-reported car crashes. Journal of Safety Research, 33(4), 431-443. doi:https://doi.org/10.1016/S0022-4375(02)00053-1

Davie, R., Panting, C., \& Charlton, T. (2004). Mobile phone ownership and usage among pre-adolescents. Telematics and Informatics, $21(4), 359-373$. doi:https://doi.org/10.1016/j.tele.2004.04.001

Fuller, E. A. (2000). The windlass mechanism of the foot. A mechanical model to explain pathology. Journal of the American Podiatric Medical Association, 90(1), 35-46. doi: $10.7547 / 87507315-90-1-35$

Gras, M. E., Cunill, M., Sullman, M. J. M., Planes, M., Aymerich, M., \& Font-Mayolas, S. (2007). Mobile phone use while driving in a sample of Spanish university workers. Accident Analysis \& Prevention, 39(2), 347-355. doi:https://doi.org/10.1016/j.aap.2006.08.006

Hill, L., Rybar, J., Styer, T., Fram, E., Merchant, G., \& Eastman, A. (2015). Prevalence of and attitudes about distracted students. Traffic Inj Prev., 16(4), 5. doi:10.1080/15389588.2014.949340

Karim, N. S. A., Darus, S. H., \& Hussin, R. (2006). Mobile phone applications in academic library services: a students' feedback survey", Campus-Wide Information Systems, Vol. 23 No. 1, pp. 35-51. . Campus-Wide Information Systems, 23(1), 35-51.

Kong, J., Zhang, K., \& Chen, X. (2013). Personality and Attitudes as Predictors of Risky Driving Behavior: Evidence from Beijing Drivers. In: Duffy V.G. (eds) Digital Human Modeling and Applications in Health, Safety, Ergonomics, and Risk Management. Healthcare and Safety of the Environment and Transport. DHM 2013. Lecture Notes in Computer Science, vol 8025. Springer, Berlin, Heidelberg. Digital Human Modeling and Applications in Health, Safety, Ergonomics, and Risk Management. Healthcare and Safety of the Environment and Transport. DHM 2013. Lecture Notes in Computer Science, 8025. 
Lucidi, F., Girelli, L., Chirico, A., Alivernini, F., Cozzolino, M., Violani, C., \& Mallia, L. (2019). Personality Traits and Attitudes Toward Traffic Safety Predict Risky Behavior Across Young, Adult, and Older Drivers. Frontiers in Psychology, 10(536). doi:10.3389/fpsyg.2019.00536

Masuri, M. G., Asib, N. A. M., Dahlan, A., \& Isa, K. A. M. (2019). Human Factors and Attitude towards Safe Driving Scale among Young Adults in Malaysia. EnvironmentBehaviour Proceedings Journal, 4(11), 203-209. doi:10.21834/e-bpj.v4i11.1726

Masuri, M. G., Samad, N. A. A., Dahlan, A., \& Isa, K. A. M. (2019). Attitude towards Safe Driving and Mobile Usage among Young Adult in Malaysia. EnvironmentBehaviour Proceedings Journal, 4(10), 171-178. doi:10.21834/e-bpj.v4i10.1638

McCartt, A. T., Kidd, D. G., \& Teoh, E. R. (2014). Driver cellphone and texting bans in the United States: evidence of effectiveness. Annals of advances in automotive medicine. Association for the Advancement of Automotive Medicine. Annual Scientific Conference, 58, 99-114. Retrieved from https://www.ncbi.nlm.nih.gov/pubmed/24776230 https://www.ncbi.nlm.nih.gov/pmc/articles/PMC4001674/

Mizenko, A. J., Tefft, B. C., Arnold, L. S., \& Grabowski, J. G. (2015). The relationship between age and driving attitudes and behaviors among older Americans. Injury Epidemiology, 2(1), 9. doi:10.1186/s40621-015-0043-6

Motiwalla, L. F. (2007). Mobile learning: A framework and evaluation. Computers \& Education, 49(3), 581-596. doi:https://doi.org/10.1016/j.compedu.2005.10.011

Palen, L., Salzman, M., \& Youngs, E. (2001). Discovery and integration of mobile communications in everyday life. Personal and Ubiquitous Computing, 5, $109-122$. Personal and Ubiquitous Computing, 5, 109-122.

Pöysti, L., Rajalin, S., \& Summala, H. (2005). Factors influencing the use of cellular (mobile) phone during driving and hazards while using it. Accident Analysis and Prevention, 37(1), 47-51. doi:10.1016/j.aap.2004.06.003

Safarpour, H., Khorasani-Zavareh, D., \& Mohammadi, R. (2020). The common road safety approaches: A scoping review and thematic analysis. Chinese Journal of Traumatology - English Edition. doi:10.1016/j.cjtee.2020.02.005

Schmidt, F. L., \& Hunter, J. E. (2015). General Technical Issues in Meta-Analysis (in Methods of Meta-Analysis: Correcting Error and Bias in Research Findings)(2 ed.). doi:10.4135/9781412985031

Sullman, M., \& Baas, P. (2004). Mobile phone use amongst New Zealand drivers. TransportationResearch Part F, 7:95-105. Transportation Research, Part F(7), 95-105.

White, K. M., Hyde, M. K., Walsh, S. P., \& Watson, B. (2010). Mobile phone use while driving: An investigation of the beliefs influencing drivers' hands-free and hand-held mobile phone use. Transportation research part F: traffic psychology and behaviour, 13(1), 9-20. doi:10.1016/j.trf.2009.09.004

Yeoh, S. F., Rashid, S. N. S. A., \& Chan, B. Y. F. (2009). Driving practices of older Malaysian drivers: The influence of knowledge, attitude and confidence. European Journal of Social Sciences, 12(1), 65-75.

Zhu, M., Rudisill, T. M., Rauscher, K. J., Davidov, D. M., \& Feng, J. (2018). Risk Perceptions of Cellphone Use While Driving: Results from a Delphi Survey. International journal of environmental research and public health, 15(6), 1074. doi:10.3390/ijerph15061074 